\title{
Hacer propio lo que es ajeno. Políticas de naturalización en América del Norte. Estados Unidos y México, siglo XIX
}

por

Erika Pani*

El Colegio de México

Este articulo hace un análisis comparativo de la evolución de las leyes de naturalización en dos naciones «nuevas» de América del norte, desde la independencia y hasta principios del siglo XX, cuando se pone fin a la «Era de puertas abiertas» durante la cual las políticas migratorias habian sido favorables a quienes venian de fuera. Revela cómo las políticas de naturalización se erigieron como espacios para la expresión, por un lado, los ideales republicanos de pertenencia, $y$, por el otro para la regulación, por parte de la autoridad, primero estatal, después federal, de la comunidad política.

Palabras clave: México; Estados Unidos de América; naturalización; migración; republicanismo.

«Naturalizar» $\mathrm{y}$ «naturalización», «naturalise» $\mathrm{y}$ «naturalization» en inglés - en sentido estricto, hacer natural algo que no lo es - son términos torpes, que parecen contener en sí mismos un contrasentido. El diccionario de la Real Academica Española los definía, en 1734, como la acción de «admitir como natural al extranjero en el propio País o lugar», como el derecho «que concede el Príncipe a los Extranjeros, para que gocen de los privilegios,

* Agradezco los sugerentes comentarios de José Moya y Pablo Yankelevich, quienes participaron en la sesión «Migración en las Américas. Integrar, seleccionar, excluir» de la XIII Reunión de historiadores de México, Estados Unidos y Canadá (Querétaro, octubre 2010) y de los alumnos del curso «Los caminos de la ciudadanía» (El Colegio de México, 2011). Agradezco también el apoyo del Programa Interinstitucional de Estudios de la Región de América del Norte. 
como si fueran naturales del Reino». El diccionario Merriam-Webster alude a un significado similar en inglés ya para mediados del siglo XVI. En la América independiente, un mundo que se concebía como «nuevo» e insuficientemente poblado, el asunto adquiriría nuevas complejidades con la «Era de las Revoluciones»: una vez rotos los lazos supuestamente naturales e indestructibles que unían al rey con sus vasallos, ¿qué iba a estructurar la comunidad política? Ahí donde la nación se proclamaba soberana, la naturalización implicaba no solo dar acceso — que podía ser parcial y estar condicionado- a los privilegios de un reino o de una ciudad ${ }^{1}$, sino abrir la puerta a la comunidad que era fuente de la autoridad política. Se trataba de un trámite legal que debía transformar al extranjero en ciudadano.

Así, a lo largo de un siglo en el que los desplazamientos de población irían en aumento, el forjar un vínculo efectivo entre la autoridad pública y los habitantes que venían de fuera iba a representar una tarea esencial y contenciosa en los nuevos países americanos, no obstante la variedad de experiencias migratorias que estos vivieron. Tanto en México, que nunca representó un foco importante de inmigración - la población extranjera nunca rebasó el 0,78\% que alcanzó en 1910 - , como en los Estados Unidos, donde desde 1860 y hasta 1930 , alrededor del $14 \%$ de la población había nacido fuera de territorio estadounidense, los extranjeros y su relación con la sociedad receptora y con el Estado plantearon problemáticas pertinaces. Este texto pretende rastrear los mecanismos con los que dos Estados surgidos del desmantelamiento de los Imperios atlánticos buscaron resolver los problemas que representaban los extranjeros que venían a instalarse en su territorio, integrándolos a la comunidad nacional.

GUERRA DE INDEPENDENCIA / GUERRA CIVIL

Tanto las trece colonias británicas como la Nueva España — casi cuarenta años después - alcanzaron la independencia por caminos tortuosos: en ambos

${ }^{1}$ Estos privilegios podían dar acceso a los bienes del común (pastos, molino, mercado, cargos públicos, etc.), así como a derechos de propiedad y la exención de ciertos gravámenes. Dentro de la Monarquía Católica, la naturalización era necesaria para que los no originarios de los reinos de Castilla y León, Aragón y Navarra pudieran emigrar legalmente a América, incluso tratándose de vasallos de la Corona. Para un estudio sobre naturalización y vecindad en la Monarquía Católica, que subraya el papel central que desempeñan en su definición los núcleos de población, véase Herzog, 2003. Para una discusión de la extranjería dentro de la Monarquía, véase Ciaramitaro, 2006. Agradezco al profesor Ciaramitaro su amabilidad por haberme facilitado su trabajo. 
casos, los colonos americanos habían reclamado, dada su acendrada fidelidad, la inserción plena en el Imperio, en igualdad de condiciones con los habitantes de la metrópoli. Quienes se reclamaban «vasallos fidelísimos» empuñaron las armas en contra de políticas metropolitanas para terminar renunciando tajantemente a la Corona. De la ruptura surgió la necesidad de fincar, sobre fundamentos distintos, un nuevo orden político. En ambos casos, los actores se esforzaron por transformar a unas colonias levantiscas en estados independientes, a una guerra civil en guerra de independencia y a unos súbditos rebeldes en ciudadanos patriotas. En junio de 1776, a más de un año de haberse iniciado la lucha armada, el Congreso continental reunido en Filadelfia declaró disuelta la relación de protección y obediencia que unía a Jorge III con los colonos americanos: afirmó que quienes residieran en las colonias, al cobijo de sus leyes, les debían lealtad. Al mes siguiente, el Congreso catalogó las iniquidades y vejaciones de que habían sido víctimas sus representados en manos del Real Bruto y declaró al mundo que las colonias unidas «eran, y por derecho debían ser, ESTADOS LIBRES E INDEPENDIENTES»².

En la Nueva España, donde insurgentes y realistas clamaban ambos defender a «Dios, la Patria y el Rey», la construcción de una nueva filiación política - definida tanto en el discurso insurgente como en el del liberalismo gaditano como «nacional»— se dio de forma más accidentada. Ya en 1808, fray Melchor de Talamantes reclamaba un Congreso Nacional Americano para ejercer, en la Nueva España, los derechos de la soberanía, estando cautivo el legítimo monarca ${ }^{3}$. Los insurgentes que se levantaron en armas en 1810 denunciaron como opresiva «la tiranía de los europeos» y se lanzaron a la guerra para que los americanos fueran «dueños y señores libres del país abundante y delicioso en que [habían] nacido» ${ }^{4}$. Al tiempo que proclamaban su lealtad a Fernando VII rechazaban la posibilidad de que las Juntas o Cortes metropolitanas pudieran dar voz a América. Hacía falta un Congreso que representara a las «ciudades, villas y lugares» de la Nueva España, único que podía dar «leyes suaves, benéficas y acomodadas a las circunstancias de cada pueblo», desterrando «la pobreza moderando la devastación del reino y la extracción de su dinero» ${ }^{5}$. Sin embargo, no fue sino hasta noviembre de 1813 - cuando, más de un año antes, las Cortes de Cádiz habían proclamado que

2 Armitage, 2007.

3 «Proyecto de plan de independencia de México», agosto 1808, Documentos, 1986: 73.

4 «Proclama a la nación americana emitida por Miguel Hidalgo en Guadalajara», 21 de noviembre de 1810; «Proclama de Morelos emitida en Cuautla», 8 de febrero de 1812, Documentos, 1986: 99; 120; 119.

5 «Manifiesto de Hidalgo», 16 de diciembre, 1810, Documentos, 1986: 104. 
eran españoles «todos los hombres libres nacidos y avecindados en los dominios de las Españas» ${ }^{6}$ - , que el congreso insurgente reunido en Chilpancingo declaró «rota para siempre jamás y disuelta la dependencia del trono español» de la América Septentrional.

De este modo y a contrapelo de la nación definida en Cádiz como comunidad trasatlántica articulada en torno al monarca católico, los diputados insurgentes concibieron a la "América mexicana» sobre bases físicas, tangibles: la religión y el nacimiento en territorio nacional determinaban la pertenencia ${ }^{7}$. Paralelamente, el que había nacido fuera - el «extranjero», y en particular el «gachupín»- llegó a encarnar dentro del imaginario insurgente al enemigo nato. De este modo, mientras que el Congreso continental de Filadelfia había intentado seducir a los mercenarios alemanes del ejército británico con promesas de tierras y derechos políticos, el jefe insurgente José María Morelos exigió que solo los americanos pudieran disfrutar de empleos públicos, y que, incluso, no se permitiera la entrada a ningún extranjero, a menos de que fueran «artesanos, capaces de instruir y libres de toda sospecha» ${ }^{8}$.

\section{TIEMPO DE DEFINICIONES}

En América, el tránsito de colonia a estado independiente resquebrajó la antigua comunidad política fincada en la lealtad al Rey. La guerra exigió, como contraparte de la invención del «otro» como enemigo, la definición de un «nosotros». Con la constitución de entidades independientes tanto en Estados Unidos como en México, hubo que fijar los criterios de pertenencia al cuerpo político, así como los lineamientos para integrar a quienes vinieran de fuera. Este proceso se llevó a cabo en un contexto posrevolucionario, fincado en una serie de ficciones que darían forma peculiar al discurso y a las prácticas políticas. La nación, integrada por ciudadanos iguales, se proclamaba soberana, y, por lo tanto, el gobierno debía representarla y articular su voluntad. La política era, por lo tanto, competitiva, y se hacía de cara al público. En los casos mexicano y estadounidense, por tratarse de sistemas que se erigieron como federales, distintas instancias de gobierno podían legítimamente apelar a la lealtad, y exigir la obediencia de los pobladores. Las relaciones entre las autoridades federales y estatales, más que reflejar una jerarquía claramente establecida, engendraban a menudo forcejeos y jurisdicciones trasla-

\footnotetext{
6 Cap. II, art. 5, en «Constitución de Cádiz», marzo 18, 1812, Tena Ramírez, 2002: 60.

7 He revisado este proceso con mayor detalle en Pani, 2009.

8 Franklin, 1905: 5-6; «Sentimientos de la Nación», Tena Ramírez, 2002: 29-30.
} 
padas. De este modo, los debates y controversias en torno a las leyes de naturalización representaron un espacio en el que se confrontaban las facciones que buscaban el poder así como distintas poderes y autoridades que reclamaban su derecho a trazar las fronteras de la comunidad política, y a prescribir los requisitos de entrada. Por lo tanto, este espacio resulta un mirador privilegiado para la expresión y confrontación de visiones distintas de lo que debían ser la ciudadanía y la sociedad.

Así, durante los primeros años de vida independiente, y con la promulgación de las primeras leyes de naturalización, tanto en Estados Unidos como en México surgieron disputas en torno a lo que debían ser los fundamentos de la pertenencia y a quién tenía derecho a abrir la puerta de la ciudadanía. Estos conflictos permanecerían vigentes, en diferentes grados, hasta bien entrado el siglo XIX. Al momento de la independencia, y a pesar de la xenofobia de que habían dado muestra algunos insurgentes mexicanos, ambos nuevos estados establecieron que la aceptación, tácita o explícita, del nuevo orden de cosas bastaba para formar parte de la nueva sociedad nacional. Como establecían los tratados de Córdoba, «alterado el sistema de gobierno», todo hombre quedaba «en el estado de libertad natural para trasladarse con su fortuna» a donde más le conviniera. De ahí que en los Estados Unidos más de 80.000 «leales» (loyalists) se trasladaran a dominios británicos ${ }^{9}$. Este principio de adhesión voluntaria subyacería también los primeros esfuerzos legislativos por normar la naturalización. A partir de 1790 en Estados Unidos y de 1828 en México, la ley estableció como requisito para volverse ciudadano que el individuo renunciara de forma expresa a toda lealtad política ajena a la de su nueva patria, y que jurara sostener la constitución, dando además, en Estados Unidos, pruebas de su «apego» — attachment - a la ley fundamental. Para asegurar los fundamentos republicanos de los nuevos gobiernos, los dos países exigirían que los futuros ciudadanos renunciaran a toda «gracia o condecoración, [...] título u orden nobiliario» ${ }^{10}$.

La «filiación deliberada» — volitional allegiance ${ }^{11}$ —, que fincaba la pertenencia política en la voluntad individual, cuadraba bien con los vientos liberales que soplaban en el espacio atlántico durante una era turbulenta en que se resquebrajaron imperios y surgieron nuevas entidades políticas. Bien

9 Wallace Brown calcula que había entre 160.000 y 384.000 loyalists, de los cuales se exilaron entre 80.000 y 192.000, de una población de 2.500.000. Brown, 1965: 250.

10 Act to establish a uniform rule of naturalization, 29 de enero de 1795 en LeMay y Barkan, 1999: 12-13; Reglas para emitir cartas de naturaleza, 14 de abril de 1828, \#563 en Dublán y Lozano, 1876-1904.

11 Kettner, XVIII (Filadelfia, 1974): 208-266, y de manera más extensa Kettner, 1978. 
pronto demostró ser, sin embargo, un principio escurridizo en la práctica, tanto por los problemas diplomáticos que acarreaba en un contexto internacional en el que la idea de la filiación perpetua seguía teniendo validez, como porque, como se puso de manifiesto de forma casi inmediata, debilitaba al Estado como garante de la integridad de la comunidad nacional. No debe sorprender que ninguna de las dos Repúblicas lo aplicara a cabalidad. Durante los tiempos revueltos que inauguró la Revolución francesa, la posibilidad de cambiar de nacionalidad se convirtió en parte del arsenal estratégico de muchos individuos que navegaban las aguas del Atlántico ondeando la bandera de la libertad, tanto para perseguir beneficios económicos como en busca de refugio político. Subieron a escena, en Europa como en América, comparsas de actores notablemente cosmopolitas, desde el Marqués de Lafayette, Thomas Paine y Casimir Pulaski hasta Xavier Mina y Gregor MacGregor ${ }^{12}$. El periodo en que empezaban a esbozarse las fronteras nacionales engendró también una patria revolucionaria trasatlántica, plurinacional y políglota que proclamaba el fin del Antiguo Régimen.

Los principios de la Revolución trasnacional representaron un desafío abierto a la autoridad de los Estados, viejos y nuevos, que buscaron afianzar su control sobre la población, y clausurar los espacios en que su autoridad se diluía ${ }^{13}$. En los Estados Unidos, muchos consideraron que la joven república debía brindar abrigo a los revolucionarios itinerantes. Incluso George Washington, tan poco dado a la retórica expansiva de algunos de sus cofrades, afirmaría que debía darse la bienvenida a «los oprimidos y perseguidos de todas las Naciones y Religiones» ${ }^{14}$. El asunto también tocaba fibras sensibles para una joven república que pretendía sentar sus reales sobre el escenario internacional. El gobierno estadounidense se escocía ante la negativa de la corona británica a reconocer las naturalizaciones en la nueva república. Frente a la política de reclutamiento forzoso de antiguos súbditos que desplegaba la armada británica, los políticos estadounidenses defenderían con vehemencia el derecho de expatriación ${ }^{15}$. Sin embargo, al enfrentarse al entusiasmo con

12 Mongey, 2009: 67-82. Rojas, 2009. Brown, 24/1: 44-71 (Londres, 2005).

13 Sobre la disyuntiva entre las tensiones que provocó, durante la Revolución francesa, la confrontación entre la construcción de la «república universal» y el Estado revolucionario, igualador y modernizador, véase Wahnich, 2010.

14 Carta de George Washington a el «Volunteer Association of the Kingdom of Ireland Lately Arrived in the City of New York», 2 de diciembre de 1783, en LeMay y Barkan, 1999: 10-11.

15 Bradburn, 2009: 101-123. De hecho, el reclutamiento forzoso de ciudadanos naturalizados por la armada británica fue uno de los irritantes que desembocó en la guerra de 1812 . Zimmerman, 1925. 
que algunos ciudadanos americanos ejercían este derecho «natural» y «sagrado», fueron mucho más circunspectos los jueces que tuvieron que lidiar con los enredos que provocaban los corsarios estadounidenses que adoptaban otra nacionalidad para facilitar sus correrías.

De este modo, en 1795, el caso de Talbot v. Janson, en el que el capitán de un navío holandés capturado por dos corsarios franceses reclamara ser indemnizado ante un tribunal en Carolina del Sur, por ser los capitanes de estos barcos nativos de Virginia, motivó a cinco de los nueves jueces de la Suprema Corte a redactar opiniones individuales para expresar posturas idénticas. Frente a la airada exaltación que del derecho de expatriación harían los abogados de los acusados ${ }^{16}$ la Corte buscó moderar y acotar este principio. Afirmó la legitimidad de la expatriación como prerrogativa, pues el hombre «no podía ser un esclavo, confinado en contra de su voluntad a un lugar particular» por la casualidad de haber nacido ahí. Pero esta facultad no podía ejercerse siempre y de cualquier forma. Los acusados, los capitanes Talbot y Ballard, se habían naturalizado franceses para poder cometer impunemente atropellos en el área circuncaribe: un objetivo ilegal no podía servir de base a la expatriación. El cambiar de patria debía hacerse de buena fe, manifestándose esta con, por lo menos, la salida del emigrante, «con su familia y propiedades» para residir en su nueva patria. William Ballard, aunque había renunciado expresamente a la ciudadanía virginiana, continuaba residiendo en los Estados Unidos ${ }^{17}$. Seguía siendo, por lo tanto y sin duda, ciudadano estadounidense y estaba sujeto a la jurisdicción de la Corte.

Uno de los temas más problemáticos para los intérpretes de la ley fue la relación contractual, basada en el consentimiento, que supuestamente vinculaba a Estado y ciudadanos. Para los legatarios de la Revolución americana esta relación consensual apuntalaba su novedoso sistema de gobierno. Sin negarla, los jueces enfatizaron la reciprocidad implícita en el contrato, por encima de su aspecto voluntario. En Talbot, el juez Iredell afirmó que en un contrato derechos y deberes obligaban ambos: la relación contractual no podía finiquitarse para no cumplir con la parte que correspondía al ciudadano. Para los estadounidenses, en 1795, una de estas obligaciones era no cazar los bar-

16 Este se articulaba esencialmente, según la defensa, en torno a las diferencias entre la ciudadanía y la filiación: la primera era «producto de un pacto», «la carta de la igualdad», «constitucional»y «renunciable». La segunda era «hija de la necesidad y del poder», una «marca de desigualdad», «personal» y «perpetua». Caso ante la Suprema Corte de Talbot $v$. Janson, 3 US 133, en http://www.law.cornell.edu/supct/html/historics/USSC_CR_0003_0133 ZS.html.

17 Opiniones de los Jueces Cushing y Paterson, en Talbot v Janson. Además, ambos barcos habían sido armados y equipados en los Estados Unidos. 
cos holandeses; por lo tanto, Talbot y Ballard habían cometido un delito. En un caso similar, el de Isaac Williams, que se había naturalizado francés y asaltado barcos británicos, el veredicto de la corte fue más lejos aún: afirmó que un pacto político involucraba a dos partes, y por lo tanto ambas tenían que acceder a su disolución. El individuo no podía expatriarse sin el consentimiento explícito del Estado ${ }^{18}$. La polarización, los temores y la violencia retórica que caracterizaron la política estadounidense durante la década de 1790 — y lo que se conoce como la «casi guerra» con Francia- contribuyen a explicar la problemática postura de la Corte. Sin embargo, incluso cuando, casi una década después, corrían tiempos más serenos, el juez John Marshall puso en duda que un ciudadano estadounidense pudiera renunciar «absolutamente» a este carácter, sin una ley que estableciera cómo hacerlo ${ }^{19}$. Los Estados Unidos no promulgaron una ley de expatriación sino hasta 1868.

En México, ya las Siete Leyes Constitucionales de 1836, que abandonaban, a favor del centralismo, el régimen federal, reconocieron como uno de los «derechos del mexicano» el «no podérsele impedir la traslación de sus personas y bienes a otro país, con tal de que no [dejara] descubierta en la República responsabilidad de ningún género» ${ }^{20}$. No obstante, en este mismo año, el gobierno mexicano reprimiría con violencia aunque poco éxito, el esfuerzo de los ciudadanos texanos por expatriarse en masa. Los texanos apelaron a una concepción contractual del vínculo político. Si se separaban de México era porque el gobierno no había cumplido con su parte del contrato, pues había dejado

de proteger las vidas, libertad y propiedad del pueblo, de quien derivan sus legítimos poderes, habiendo sido instituido para la promoción de su felicidad, y que lejos de ser garantía para el goce de esos inestimables e inalienables derechos, se convierte en un instrumento en manos de gobernantes malvados ${ }^{21}$.

Ante una crisis así, los texanos no podían sino «abolir este gobierno, y crear otro en su lugar». En cambio, para el gobierno mexicano estos «patriotas» representarían unos traidores a los que no podría castigar ${ }^{22}$. Tampoco

18 Caso ante el tribunal de distrito de Williams, 17, 708 Circuit Court, D Cnt, 29F Cas 1330; 1799 US App.

${ }_{19}$ Caso ante la Suprema Corte de Murray v. The Charming Betsey, 6 US (2 Cranch) 64 (1804) en http://supreme.justia.com/us/6/64/case.html.

20 Primera ley constitucional, Art. 2, VI, Tena Ramírez, 2002: 206.

21 Texas Declaration of Independence, Washington-on-the-Brazos, 2 de marzo de 1836, en http://avalon.law.yale.edu/19th_century/texdec.asp.

22 Véanse los argumentos similares esgrimidos por José Antonio Navarro, quien firmara el Acta de Independencia texana, y que después de participar en la expedición texana a San- 
pudo hacer mucho para controlar las acciones de los agiotistas españoles, que, como los filibusteros estadounidenses de la década de 1790, recurrieron a la estrategia del cambio de nacionalidad, aunque ya sin levantar el estandarte revolucionario, para convertir sus préstamos al gobierno mexicano en deuda soberana $^{23}$. Aunque no volvió a enfrentarse a un desafío de la magnitud del de Texas, el normar a la población que se hallaba bajo su jurisdicción representó, como se verá, una tarea ardua para el Estado mexicano.

Las nuevas formas de pensar la pertenencia política autorizaban la posibilidad de dejar de ser ciudadano, práctica que sin embargo resultó conflictiva. El movimiento en sentido inverso - el volverse miembro de una nación distinta - fue también, en ciertos casos, problemático. Durante la primera década de vida independiente, ambos jóvenes estados buscaron cerrar las puertas de la ciudadanía a elementos que consideraban indeseables, no obstante el deseo que estos expresaron de pertenecer. En Estados Unidos, varios estados de la federación promulgaron leyes para restringir los derechos de quienes durante la revolución habían apoyado la causa del rey ${ }^{24}$. En Nueva York, Alexander Hamilton protestaría en contra de la discriminación en contra de los antiguos loyalists. La filiación política debía fincarse en la sujeción a las leyes, y no en la adhesión entusiasta al orden revolucionario. «El admitir - escribía - que los súbditos pueden renunciar a placer a su lealtad al estado del que son miembros [...] es un principio contrario a la ley y subversivo de todo gobierno.» Con esto, el connotado federalista desafiaba uno de los elementos clave del nuevo orden, redefiniendo, al mismo tiempo, otro de sus conceptos medulares: la libertad. Esta no era, como parecían clamar los demagogos, «una mera exención del encarcelamiento», sino «el goce de los privilegios comunes a todos los sujetos bajo un mismo gobierno». La revolución debía promover la «tolerancia en política», como lo había hecho ya en asuntos de religión: nadie podía ser considerado un enemigo del gobierno por «las especulaciones» que pudiera entretener sobre su forma y legitimidad ${ }^{25}$.

Dentro de una línea similar, en México, en 1827, en un contexto de crisis económica y política y frente a la amenaza de reconquista española, el grupo político de los yorkinos, montados sobre un difundido reclamo popular, exigió

ta $\mathrm{Fe}$ en 1841, fue apresado por tropas mexicanas y juzgado como traidor a la patria. Navarro escapó antes de ser ejecutado. Reséndez, 2005.

23 Pi-Suñer, 1995. Rabadán, 76 (México, 2006): 65-93. Meyer, 1999.

${ }^{24}$ Baseler, 1998.

25 Alexander Hamilton, «Phocion Letters», 1790, en http://teachingamericanhistory.org/ library/index.asp?document=2360. Hamilton también temía que estas leyes, que contravenían el tratado de paz de 1783, acarrearan problemas en la relación de Estados Unidos con Gran Bretaña. 
la expulsión de los españoles cuya presencia, aseguraban, negaba la independencia, mermaba la prosperidad y ponía en riesgo la supervivencia de la república. Sus opositores insistieron que los españoles residentes eran ciudadanos mexicanos por los tratados de Córdoba, y porque eran vecinos respetuosos de la ley. No se les podía privar de este «derecho [...] por el simple hecho de haber nacido en España». Algunos «gachupines» seguían quizá suspirando por el orden virreinal, pero, como exclamaba un folleto, "¿a dónde iríamos a parar y qué sería de las naciones si se erigiesen en crímenes las opiniones y deseos?» No obstante, los promotores de la expulsión fueron tajantes: esta era deseada, vehementemente, por el pueblo soberano, $\mathrm{y}$, como afirmaba un periódico radical en la ciudad de México, «el que [era] árbitro para adoptar a México por su patria no por eso [habría] de reputarse luego por ciudadano mexicano» ${ }^{26}$. Cuando se trataba de los malqueridos de la República, tories por un lado, gachupines por el otro, y a pesar de la inconsistencia ideológica que esto implicaba, la inserción del individuo en el cuerpo político no dependía de su voluntad, sino de la venia del Estado.

\section{LA MECÁNICA DE LA NATURALIZACIÓN}

\section{Las instancias de gobierno}

Como se ha mencionado ya, a lo largo del siglo XIX, en ambos países, aunque de formas y en grados distintos, surgieron controversias que giraron tanto en torno a lo que el extranjero tenía que ser y hacer para dejar de serlo, como a quién debía encargarse de dejarlo entrar. Así, a pesar del aparente consenso, en ambos casos, de que fuera el gobierno nacional el que se ocupara de la naturalización - como quedó establecido, sin mayor discusión, en la constitución estadounidense de 1787 y en la mexicana de 182427 , otras instancias de gobierno reclamaron la facultad de dibujar las fronteras del

26 «Política. Discurso sobre la expulsión de naturales y ciudadanos de esta República nacidos en España», El Sol, México, 14 de septiembre de 1827; «Política. Breve examen de los discursos publicados en El Observador de la República Mexicana», en El Amigo del pueblo, México, 24 de octubre de 1827.

27 Constitución de los Estados Unidos, Art. 1, Sección 8-4; Constitución Federal de los Estados Unidos Mexicanos, Art. 49-XXVI. En la convención de Filadelfia, la propuesta de que fuera el gobierno federal el que se encargara de establecer una «regla uniforme de naturalización» se incluía en el «Plan de Nueva Jersey», la menos centralista de las propuestas que sirvieran de base a la discusión de la nueva constitución. Para el texto del plan, véase http://avalon.law.yale.edu/18th_century/debates_615.asp\#pat. 
cuerpo político. Así, la mayoría de las constituciones estatales mexicanas de la Primera República otorgaron a las legislaturas estatales la facultad de normar la naturalización que el congreso federal tenía supuestamente en exclusiva. Además, ambos regímenes - el mexicano hasta 1836 - dejaron en manos de los estados la prerrogativa de definir los requisitos para la participación política. En Estados Unidos, este doble nivel de pertenencia y la relación indeterminada entre la ciudadanía estatal y la federal mantuvieron la definición de la ciudadanía estadounidense en una profunda ambigüedad jurídica, que pondría de manifiesto la decisión de la Suprema Corte en el caso de Dred Scott. En 1857, al fallar sobre la demanda de un esclavo que reclamaba su libertad, como ciudadano estadounidense, por haber sido transportado a un territorio en donde la esclavitud estaba prohibida, el juez Roger B. Taney dictaminó que los afroamericanos no eran ni podían ser ciudadanos de los Estados Unidos ${ }^{28}$. No fue sino hasta la ratificación de la catorceava enmienda en 1868 que se estableció una definición clara, aunque contenciosa, de quién era ciudadano estadounidense, basada en el nacimiento sobre el territorio y la sujeción a la jurisdicción federal.

De este modo, las polémicas en torno al grado de inclusión de los extranjeros residentes provocaron conflictos entre los gobiernos federal y estatales. Estos enfrentamientos a menudo articulaban rivalidades políticas más que visiones distintas de lo que debía ser la sociedad. Entre 1798 y 1800, en Estados Unidos, los republicanos capitaneados por Thomas Jefferson y James Madison se opusieron a una serie de leyes excluyentes promovidas por los federalistas. En su opinión, las leyes de extranjería — que permitía al Ejecutivo expulsar a todo extranjero que percibiera como peligroso-, naturalización - que extendía el periodo de residencia exigido a catorce años- y sedición - que criminalizaba la crítica al gobierno - violentaban los derechos individuales, hacían casi imposible la integración de los inmigrantes y otorgaban facultades excesivas al Ejecutivo. Su argumento jurídico para promover los derechos de los extranjeros como hombres y ciudadanos en potencia se fincó en la cláusula constitucional que prohibía la intervención de la legislatura federal en «la Migración o Importación de aquellas Personas que los Estados [...] consideren apropiado admitir, antes del año 1808». Así, la disposición que protegía la facultad de los estados para introducir esclavos fue esgrimida como prueba de que la facultad de normar la integración de quienes venían de fuera a la sociedad estadounidense pertenecía a las entidades fede-

28 Caso ante la Suprema Corte de Dred Scott v. Sanford, 60 U.S. (19 How.) 393 en http://www.law.cornell.edu/supct/html/historics/USSC_CR_0060_0393_ZS.html. 
radas $^{29}$. De manera parecida, en 1827 , cuando algunos políticos mexicanos identificados con la logia masónica «escocesa», exigieron que la federación impidiera a las legislaturas estatales expulsar a los españoles residentes, sus opositores, los yorkinos, negaron que el poder nacional tuviera la facultad de «proteger por leyes sabias y justas los derechos del hombre y del ciudadano», a pesar de que así lo establecía el acta constitutiva de $1824^{30}$. Esta disposición, alegaron, no había sido reglamentada por ley, y eran los estados «libres y soberanos» quienes debían velar por la salud de su población. Tenían derecho, por lo tanto, a extirpar aquello que los lastimaba.

En México, este tipo de enfrentamientos entre estados y federación no vuelve a surgir después de 1830 - lo que puede deberse a una centralización más exitosa de estos asuntos que en el caso del vecino del norte, o a la presencia numéricamente insignificante de los extranjeros en México-. En Estados Unidos, en cambio, los temas de inmigración y naturalización representaron, de forma consistente, temas contenciosos dentro de la agenda nacional, sobre todo hacia las últimas décadas del siglo. Después de la guerra civil (1861-1865), la autoridad del poder federal se afianzó frente a los esfuerzos de los estados por regular la inmigración y restringir el acceso de ciertos grupos a los derechos ciudadanos. El actor central de este proceso fue el poder judicial. Esta es quizá la diferencia más llamativa del componente institucional de los procesos de naturalización en las dos repúblicas vecinas. En la del norte, la naturalización es un proceso judicial: desde la primera ley federal de naturalización de 1790, tanto la declaración de intención de volverse ciudadano como su ratificación y el juramento de fidelidad se llevaban a cabo «en corte abierta». El acceso a la ciudadanía era, por lo tanto y por lo menos hasta 1906, un asunto justiciable, por implicar derechos adquiridos.

En cambio, al sur de la frontera, el convertirse en ciudadano era un proceso administrativo que en el siglo XIX involucraba a distintos poderes y niveles de gobierno. Por regla general - los requisitos cambiaron, según las leyes promulgadas en 1828, 1842, 1846, 1854, 1864 y 1886, para los colonos, para los propietarios de bienes raíces, para quienes se casaran con mexicana o tuvieran hijos mexicanos, y quienes hubieran desempeñado cargos públicos o servido a la República con las armas - el interesado debía avisar, con un año de anticipación, al ayuntamiento de su deseo de naturalizarse. El proceso se tramitaba a través del gobernador del estado en el que residía el extranjero. El solicitante debía levantar ante un juez un informe judicial para demostrar

\footnotetext{
29 Constitución de los Estados Unidos, Art. 1, Sección 9-1.

30 Acta constitutiva de la federación, 31 de enero, 1824. He analizado estas leyes excluyentes con mayor detalle en Pani, 65/2 (Filadelfia, 2008): 217-243.
} 
que cumplía con los requisitos de buena conducta, religión — hasta 1857—y autonomía económica que establecía la ley. La intervención del poder judicial se limitaba, entonces, a asentar una verdad. Finalmente, la Secretaría de Relaciones emitía un dictamen. De ser positivo, el presidente podía entonces firmar - o no- la carta. La naturalización era, en este caso, un acto de gracia, en aquel de justicia ${ }^{31}$.

El proceso para obtener la ciudadanía mexicana fue, durante el siglo XIX, más complicado, más burocrático, y menos transparente, y quizá también menos predecible, en tanto que la resolución de conflictos en el estadounidense creaba precedente. Por otra parte, el papel central que desempeñaba en los procesos de naturalización un poder judicial facultado para decir lo que la ley significa - to say what the law is ${ }^{32}$ - restringió el espacio de maniobra tanto de los intereses locales como del poder federal, en lo que tocaba a los extranjeros que querían integrarse a la sociedad nacional. Así, en 1897, el tribunal federal de distrito de Texas ratificó la solicitud de ciudadanía de Ricardo Rodríguez, un inmigrante mexicano analfabeto, residente en San Antonio. Aunque el solicitante no era «ni blanco, ni africano, ni descendiente de africano», como lo exigía la ley de 1870 , y de que no sabía cómo funcionaba el gobierno estadounidense, el juez Thomas S. Maxey arguyó que la extensión general de la ciudadanía a los mexicanos que poblaban los territorios anexados en 1848 por medio del tratado de Guadalupe-Hidalgo justificaba que se naturalizara «individualmente» a los ciudadanos de México que llenaban los requisitos de ley. Esta, agregó, no discriminaba a los ignorantes ${ }^{33}$.

Dentro de la misma línea, durante las últimas décadas del siglo, la Suprema Corte actuó para mitigar la legislación anti-china del estado de California. En 1886, en el caso de Yick Wo, la Corte invalidó una ordenanza municipal de la ciudad de San Francisco, que establecía una serie de medidas draconianas para las lavanderías, las mismas que se aplicaban — con «ojo maligno y mano inequitativa», diría el juez Matthews - solo a los establecimientos que eran propiedad de chinos. La Corte determinó que las disposiciones de la catorceava enmienda para proteger la vida, la libertad y la propiedad de los individuos eran «universales en su aplicación a toda persona que esté bajo la jurisdicción territorial [de los Estados Unidos], sin tomar en cuenta diferencias de raza, color o nacionalidad, y la protección equitativa de las leyes es un

\footnotetext{
31 Agradezco a Carlos Garriga sus sugerentes comentarios sobre este tema.

32 Caso ante la Suprema Corte de Marbury v. Madison, 5 U.S. (1 Cranch) 137 (1803) en http://www.law.cornell.edu/supct/html/historics/USSC_CR_0005_0137_ZS.html

33 De León, 1979. Foley, 2004.
} 
compromiso con la protección de leyes iguales $»^{34}$. Un año después los miembros de la Suprema Corte anularon la decisión de un oficial migratorio en San Francisco que no dejó desembarcar a un trabajador de ascendencia china, nacido en California, por contravenir las leyes de exclusión de inmigrantes chinos que el Congreso venía promulgando desde 1882. La Suprema Corte declaró que según la catorceava enmienda constitucional, eran ciudadanos de los Estados Unidos todos los nacidos en su territorio y sujetos a su jurisdicción, independientemente del estatus — ilegal — o carácter —indeseable — de sus padres ${ }^{35}$.

Llama la atención que la Corte emitiera estas opiniones al tiempo que ratificaba las medidas del Congreso para limitar la inmigración china, en una serie de decisiones que aislaron la legislación migratoria de los controles constitucionales usuales ${ }^{36}$. La Corte insistió entonces en la obligación que tenía el Estado de proteger los derechos civiles y económicos de los chinos residentes en Estados Unidos — que no sus derechos políticos o a la igualdad social, como pondrían de manifiesto los casos de los Slaughter-House Cases (1873) y Plessy $v$. Ferguson (1896), que legitimaron la segregación legal de la población afroamericana en los estados del $\mathrm{Sur}^{37}$ - No obstante, frente a quienes venían de fuera, el Tribunal Supremo fortaleció las prerrogativas y amplió la libertad de acción del Estado, al determinar que su autoridad sobre la inmigración provenía, no de la constitución, sino - al igual que la facultad de repeler una invasión armada - de los «poderes inherentes a la soberanía» ${ }^{38}$.

34 Caso ante la Suprema Corte de Yick Wo v. Hopkins, 118 U.S. 356 en http://supreme. justia.com/us/118/356/case.html. Véase sobre todo Salyer, 1995.

35 Caso ante la Suprema Corte de US v. Wong Kim Ark, 169 US 649 (1898) en http:// www.law.cornell.edu/supct/html/historics/USSC_CR_0169_0649_ZS.html.

36 Véase entre otros Schuck, 84/1 (Nueva York, 1984): 1-90.

37 Caso ante la Suprema Corte de los mataderos de Nueva Orleans (Slaughter House Cases), 38 U.U. 36 (1873) en http://www.law.cornell.edu/supct/html/historics/USSC_CR_ 0083_0036_ZO.html, y el caso ante la Suprema Corte de Plessy v. Ferguson, 163 U.S. $53 \overline{7}$ (1896) en http://www.law.cornell.edu/supct/html/historics/USSC_CR_0163_0537_ZS.html.

${ }_{38} \mathrm{La}$ Corte se apartaba con esto de la que había sido su postura desde mediados del siglo XIX, que fincaba la autoridad federal sobre la inmigración en la facultad constitucional que tenía el gobierno federal de «regular el comercio con las naciones extranjeras, y entre los estados, y con las tribus indias» (Art. I, sección 8) Cleveland (Austin, 2001). Alienkoff, 2001. 


\section{Los criterios de inclusión}

Como se ha mencionado ya, en ambas repúblicas, las leyes de naturalización encarnaron visiones de lo que el extranjero debía ser y hacer para dejar de serlo. Los requisitos fueron cambiando según las percepciones y la dinámica política. Así, en los Estados Unidos las leyes de naturalización representaron un espacio de confrontación partidista, mientras que en México - donde los extranjeros eran pocos y los que se naturalizaban menos- esta legislación puso de manifiesto lo que se percibía como la necesidad de reforzar a un Estado que se enfrentaba constantemente a los reclamos de otras naciones por vejaciones - reales o inventadas - en contra de sus ciudadanos. Las leyes de naturalización se convirtieron entonces en un instrumento para afianzar la jurisdicción del aparato gubernamental sobre una población extranjera residente que era de aquí y de allá.

Ambas naciones americanas, que se imaginaban necesitadas de población, consideraron importante establecer mecanismos para integrar a la población que venía de fuera. En los Estados Unidos, entre 1790 y 1802 se promulgaron cuatro leyes de naturalización. Salvo la ley de 1798, producto aberrante de los temores que desatara la «casi guerra» con Francia y de los pocos atinados esfuerzos del partido federalista para permanecer en el poder, esta legislación sentó bases duraderas, dando forma al proceso de naturalización hasta la primera década del siglo XX. Se trataba de un proceso racista - para solicitar la ciudadanía había que ser libre y blanco-, y consecuente, como lo fue también el mexicano, con la mentalidad patriarcal de la época, quedando naturalizados en cabeza del padre, la esposa y los hijos menores. Pero resultaba también eficiente y abierto: tras un periodo relativamente corto de residencia — dos años según la ley de 1790, cinco según las de 1795 y 1802, acreditando el solicitante llevar además por lo menos un año radicado en el estado-, «todo extranjero» podía convertirse en ciudadano.

Para ello, debía renunciar, ante cualquier tribunal, a los vínculos políticos anteriores, demostrar ser hombre de «buen carácter moral», estar comprometido con los principios de la constitución y mirar con buenos ojos «el buen orden y la felicidad» de los Estados Unidos. A partir de 1795, el candidato debía renunciar a todo título nobiliario. A partir de 1798, y para evitar naturalizaciones apresuradas, irreflexivas o interesadas, se le exigió también dejar registro previo ante un tribunal de su intención «de buena fe» de convertirse en ciudadano — cinco años antes según la ley de 1798, dos a partir de 1802 - . La ley de 1802 apuntaba además que el juramento del 
interesado no podía probar que cumplía con el periodo de residencia exigi$\mathrm{do}^{39}$. En la práctica, sería el testimonio de otro - rápidamente se establecería que el de algún ciudadano estadounidense - el que serviría de prueba para demostrar que el solicitante llenaba los requisitos de residencia y cumplía con los criterios subjetivos de moralidad y convicción política para convertirse en ciudadano ${ }^{40}$.

Durante gran parte del siglo XIX, las leyes sobre el tema sirvieron sobre todo para ajustar y clarificar estas disposiciones: para naturalizar a los hijos y viudas de aquellos solicitantes que fallecían entre la declaración de intención y su ratificación (marzo 26, 1804), para asegurar que el periodo de residencia fuera de cinco años ininterrumpidos (marzo 3, 1813); para determinar la nacionalidad de los hijos de ciudadanos estadounidenses nacidos en el extranjero - considerados estadounidenses a menos de que el padre no hubiera residido nunca en los Estados Unidos-, así como la de las mujeres casadas - cuya nacionalidad seguía la del marido (mayo 14, 1834, febrero 10, 1855); y para establecer requisitos menos estrictos para naturalizar a aquellos que hubieran llegado a los Estados Unidos como menores de edad (mayo 26, 1824) - . En 1862, durante la guerra civil, el Congreso de la Unión dispuso abrir las puertas de la ciudadanía a todo extranjero que sirviera voluntariamente en las fuerzas armadas. En general, estas reformas resultaron poco polémicas, lo que sugiere un consenso generalizado sobre la necesidad de asimilar de forma eficiente y profunda a los elementos exógenos. Consistentemente, los legisladores estadounidenses rechazaron crear niveles diferenciados de ciudadanía: el ciudadano naturalizado tenía el mismo derecho a la protección del gobierno que aquel que lo era por nacimiento, y podía participar plenamente en la vida pública. La ley establecía restricciones de residencia para ciertos puestos de elección popular — nueve años para ser senador, siete para ser diputado - pero no excluía al ciudadano naturalizado sino del cargo de presidente.

En este contexto, la controversia excepcional arroja luz sobre la forma en que este tipo de legislación podía constituir un campo de enfrentamiento entre grupos de poder que, más que buscar una construcción particular de la pertenencia, esperaban granjear alguna ventaja sobre el rival político. La polémica revelaba, más que visiones distintas de lo que debía ser la sociedad, las fallas geológicas que estructuraban silenciosamente el discurso político de

\footnotetext{
39 Las leyes de naturalización de los Estados Unidos en Le May y Barkan, 1999.

40 Véanse las peticiones de naturalización presentadas ante el tribunal de circuito de Filadelfia a partir de 1790, en National Archives Record Administration (NARA) M1522. Para 1830 se utilizan ya formatos impresos que indican que el testigo es «ciudadano americano».
} 
los legisladores estadounidenses. Así, en 1795, los diputados republicanos - con excepción notable de James Madison - buscaron exhibir las simpatías aristocratizantes de sus rivales federalistas, proponiendo como requisito para la naturalización el que los solicitantes renunciaran a cualquier título nobiliario, pues estos «sólo daban a una clase peculiar de hombres el derecho a ser insolentes, y a otra el de ser mezquinos y rastreros». Los republicanos condenaron la medida por redundante, «frívola e ineficaz». No obstante, el diputado Dexter replicó pidiendo que, en consecuencia con los principios republicanos que se exaltaban, se exigiera también que el solicitante se pronunciara en contra de la propiedad esclava ${ }^{41}$.

La malograda propuesta del federalista causó escándalo; fue tachada de «monárquica» y «despótica», pues sugería que la cámara de representantes tenía derecho a determinar «el tipo de propiedad» que podían poseer los ciudadanos. En consecuencia, y tras un largo y penoso debate, la propuesta republicana fue aprobada, la de los federalistas rechazada. Sería una de las últimas veces, hasta finales de los 1840, en que el Congreso debatiría el tema de la esclavitud ${ }^{42}$. Lo que en realidad podía reducirse a las maniobras políticas de los partidos para desprestigiar al rival ponía de manifiesto la fragilidad del diálogo legislativo si se introducía el tema explosivo de la esclavitud.

Después de la Guerra Civil, la ratificación de la catorceava enmienda, que aseguraba el estatus de ciudadano independientemente del «color, raza o antiguo estado de servidumbre» del individuo hizo necesaria la reforma de la ley de naturalización. Desde julio de 1867, Charles Sumner, el senador radical por Massachusetts, propuso que la ley admitiera a «todo extranjero», sin distinción de color. No obstante, la controvertida ley de 1870 refleja menos este impulso igualitario que el empeño de los republicanos por garantizar el «sufragio honesto», purificando un proceso electoral que, dada su apertura, se prestaba al fraude y a la cooptación de inmigrantes incautos por parte de la maquinaria partidista demócrata. Tanto el esfuerzo de los menos por asegurar «derechos iguales de todos los hombres, de todo clima y raza» como las propuestas para asegurar elecciones más limpias y ordenadas «americanizándolas» se estrellaron en contra de diferentes escollos.

Los demócratas sureños deploraron lo que veían como una nueva artimaña republicana - como la imposición del «gobierno ignorante y brutal del negro en el Sur»—- para debilitar a su sección y a su partido. Otros diputados

41 Page, Sedgwick, Dexter, 21 de enero de 1795, 3rd Congress, 2nd session, en Annals of Congress: 1035-1057.

42 McDowell, 2 de enero de 1795, 3rd Cong., 2nd ses., en Annals of Congress: 1041-1048. Véase también Bradburn, 2009: 133-138. 
quisieron dar voz a los ciudadanos nacidos en el extranjero: no debía alterarse un esquema que había redundado en beneficio de la nación. La ley propuesta complicaba tanto el proceso - exigiendo que la naturalización se llevara a cabo ante tribunales federales, aumentando los requisitos para la identificación del solicitante, prohibiendo que el proceso se llevara a cabo cerca de las elecciones - que restringiría el acceso a la ciudadanía a hombres valiosos aunque poco sofisticados. Finalmente, los representantes de los estados del Pacífico rechazaron, con enorme virulencia, la posibilidad de que se naturalizara a los inmigrantes asiáticos, y particularmente los chinos ${ }^{43}$. La ley, que permitía la naturalización de todo extranjero «blanco» o de «ascendencia o naturaleza (nativity) africana», mantuvo entonces la discriminación racial dentro del proceso de naturalización. Puede incluso argüirse que la «blancura» se volvió más importante durante la última década del siglo, cuando aumentó el número de inmigrantes del medio oriente y del sureste asiático ${ }^{44}$. El grueso de la ley se ocupaba, por otra parte, de establecer una serie de sanciones - multas y prisión - para evitar el fraude —el perjurio, la utilización de certificados de nacionalidad ajenos o falsos, etc.—, así como medidas — que fueron revocadas un año después - para acrecentar la vigilancia del proceso electoral.

La ley de 1903, y sobre todo la de 1906, se inscriben dentro del desencanto democrático que ya anunciaba el debate de 1870 , y de un sentimiento anti-inmigración bien articulado y en ascenso desde la década de 1880. Encarnaron por lo tanto rupturas más profundas. Significaron la institución de una burocracia federal —el Buró de inmigración y naturalización- que debía encargarse del proceso - de hecho supervisarlo-, y la implementación de criterios más estrictos tanto para identificar al solicitante como para validar la evidencia que presentaba. Estas leyes implicaron también un cambio en la forma de concebir aquellos indicadores que constituían al solicitante como persona «de buen carácter moral», dispuesto a «sostener la constitución de los Estados Unidos». Así, en la estela del asesinato de William McKinley en manos de un supuesto anarquista cuyo nombre sonaba extranjero, el congreso prohibió, en 1903, la naturalización de personas «opuestas a todo gobierno organizado ${ }^{45}$. Por su parte, la larguísima —ocupa más de cuarenta páginas en el código de estatutos - y complicadísima ley de 1906 buscó burocratizar

43 Véase Howe; Eldridge; Shumaker y Morton; Fitch, Haldeman, Stewart, 9 junio, 25 de junio de 1870, 41st Cong, 2nd ses., Congressional Globe: 4266-4275; 4834-4843.

44 Haney López, 1997.

45 Ley de 3 de marzo de 1903. McKinley había sido asesinado en 1901 por León Czolgoz. 
un proceso judicial que se había llevado a cabo de manera regular, con pocas variaciones y de manera relativamente homogénea durante más de un siglo, y que había permitido que para 1900 , el $56,9 \%$ de los adultos varones nacidos en el extranjero se hubiera convertido en ciudadanos estadounidenses ${ }^{46}$.

Esta ley, aclamada por sus autores como «selectiva y no restrictiva», ponía en manos de una nueva instancia del gobierno federal el registro de los extranjeros llegados a los Estados Unidos. Sus funcionarios debían recabar nombre, edad, ocupación, altura, complexión, color de ojos y cabello, fechas de nacimiento, lugar de residencia antes de embarcar y nacionalidad, lugar donde pensaba radicar en los Estados Unidos, fecha de desembarco, y nombre del navío. El Buró emitía entonces al inmigrante un certificado que constituiría su prueba de residencia. Además, proveería a los tribunales formatos uniformes para la declaración de intención y su ratificación, impresos en papel de seguridad. La petición de ratificación debía ser verificada por dos testigos «confiables», ciudadanos de los Estados Unidos. El procurador general tenía derecho a aparecer en los tribunales e interrogar al solicitante y a los testigos, y a presentar evidencia en contra de que se le concediera la ciudadanía. El abogado de la nación tenía además el deber de anular los certificados de ciudadanía obtenidos de forma fraudulenta. Con esta ley, el congreso ratificaba la exclusión de los anarquistas, a la que sumaba la de los polígamos, esperando con esto coartar el poder político de los mormones en Utah y otros territorios del oeste. La ley excluía también a quienes no pudieran hablar inglés, a menos de que estuvieran físicamente incapacitados para ello.

Durante el debate de la ley, si bien no faltó quien insistiera en lo nefasto que resultaba siempre aumentar el número de burócratas en Washington ${ }^{47}$, fue esta última restricción la que generó mayor desacuerdo entre los diputados. Se arguyó que discriminaba en contra de aquellos «buenos inmigrantes» que venían a trabajar para construir una vida mejor y que tenían un nivel de educación más que aceptable, pero que muchas veces formaban comunidades aparte, y por lo tanto conservaban su lengua y su cultura. Se condenó con gran vehemencia la discriminación en contra de los trabajadores, que no tenían tiempo de aprender inglés. La ley era un dispositivo para «dejar fuera a los laboriosos y admitir a los locuaces». Otros temieron que la nueva ley impidiera la naturalización de la mayoría de los inmigrantes, lo cual daría origen

46 Croxton, 1911: 431. Un 8,2\% adicional había ya registrado su intención de convertirse en ciudadano.

47 Fitzgerald, de Nueva York; Mann, de Illinois, 2 de junio de 1906, 59th Cong., 1st ses., Congressional Record: 761; 7767-7768. 
a una masa de población que gozaba de derechos, pero no contribuía a soportar las cargas de la sociedad ${ }^{48}$.

A pesar de que el legislativo estadounidense llevaba años impulsando la restricción de la inmigración por medio de la exclusión de quienes no supieran leer y escribir - la primera ley que incluía este requisito fue aprobada en 1896, y vetada por el presidente-, los diputados se resistieron, en 1906, a establecer como requisito para la ciudadanía el saber leer y escribir: no querían dejar fuera a aquéllos que «no entendían a profundidad la ciencia del idioma» pero que podían constituir buenos ciudadanos. Sin embargo, creían que quienes no «se mezclaban con gente de habla inglesa, no leían libros en inglés, no asimilaban el inglés de todas las formas posibles», no podían sino seguir siendo «extranjeros de hecho, como lo eran todavía en su mente» ${ }^{49}$. Para admitir a un extranjero a la comunidad política, los defensores de la versión final de la ley buscaban establecer un indicador de asimilación, no un nivel mínimo de educación.

La comparación con las leyes de naturalización mexicanas es sugerente, por los puntos de contacto y divergencia que revela dentro de los proyectos de construcción de Estado y Nación en las dos repúblicas vecinas. La primera ley de naturalización de abril de 1828 buscaba, al igual que la estadounidense, abrir la puerta a los hombres «buenos» que hubieran residido en el país durante dos años continuos. Más que en el caso estadounidense, la ley mexicana insistía en la «utilidad» de los nuevos integrantes de la comunidad. Aunque la legislación mexicana no estableció nunca explícitamente criterios de raza, la religión — católica - representó un requisito legal hasta 1857. Durante la difícil década de 1840, en un contexto de creciente confrontación con los Estados Unidos, y de mayor dependencia de los créditos que le facilitaban, a un costo enorme, los agiotistas mexicanos y extranjeros, el gobierno emitió una serie de medidas contradictorias, con la esperanza quizá de desactivar la relación potencialmente explosiva entre los extranjeros y el Estado mexicano. Así, restringió los derechos de los extranjeros residentes - prohibiéndoles, por ejemplo, en marzo de 1842, el derecho a comprar bienes raíces en estados limítrofes, y, en septiembre de 1843, el ejercer el comercio al menudeo.

48 Wharton, Steeneson de Minnesota, refiriéndose específicamente a los escandinavos, Cockran, Pollard, Campbell, 2 de junio de 1906, 59th Cong., 1st ses., Congressional Record: 7770-7783.

49 Wharton, Bonynge de Colorado, Bennet de Nueva York, 2 de junio de 1906, 59th Cong., 1st ses., Congressional Record: 7770; 7775-7776. 
Por otra parte, Antonio López de Santa Anna, en recompensa al apoyo que había recibido de algunos agiotistas extranjeros para acceder al poder, estableció, por un lado, una serie de políticas que sentaron las bases de un trato preferencial para algunos de los acreedores de la Hacienda pública. Por otro, la legislación buscó allanar el camino de los extranjeros que querían dejar de serlo. Así, se permitió a los españoles nacionalizados tras la independencia recuperar su nacionalidad originaria, transformándose los montos que habían prestado al gobierno mexicano en deuda extranjera con la firma de las convenciones diplomáticas de 1844 y 1847. Paralelamente, se simplificaron los trámites de naturalización, eliminando los requisitos de residencia, concentrando el proceso dentro del poder ejecutivo, y otorgando la naturalización a quienes sirvieran en el ejército y armada nacionales ${ }^{50}$.

A partir de entonces, con excepción de una ley inscrita dentro de la misma línea que en agosto de 1864 ofreciera premiar con terrenos y la ciudadanía a los extranjeros que sirvieran en el ejército mexicano, las leyes pretendieron definir y normar al mismo tiempo el derecho de extranjería y el de naturalización, con la esperanza de deslindar un campo resbaladizo, reforzando la autoridad del Estado sobre una población numéricamente poco importante pero cuya capacidad de transformar los pleitos internos en incidentes diplomáticos la hacía peligrosa. Ya la ley de 1828 contemplaba que los colonos que, como propietarios de tierra, venían a residir permanentemente a la República, fuesen considerados como mexicanos después de un año. Posteriormente, la ley de enero de 1854 procuró señalar con precisión quién era extranjero «para efecto de las leyes», qué tenía que hacer para dejar de serlo, y quién no podía ser admitido como ciudadano (los súbditos de naciones con los que México se encontrara en guerra, los piratas, los tratantes de esclavos). La ley obligaba a los extranjeros a pedir una carta de seguridad y a renovarla anualmente. No podían gozar de derechos políticos, obtener beneficios eclesiásticos ni ejercer la pesca ni el comercio de cabotaje o de altura ${ }^{51}$.

La constitución de 1857 y la ley de extranjería de naturalización de 1886 que reglamentaba los preceptos constitucionales establecieron los parámetros del proceso hasta 1917. Estos documentos ponen de manifiesto el nacionalismo timorato de una clase política liberal, que buscaba fincar el estado de

50 Decreto \#2304, 11 de marzo de 1842, decreto \#2668, 23 de septiembre de 1843, decreto \#2377, 10 de agosto de 1842, decreto \#2900, en Dublán y Lozano, 187. Sobre la relación entre el gobierno mexicano y los empresarios extranjeros, véase Tenenbaum, 1985. Rabadán, 2000: 166-209. Sobre los españoles, véanse referencias nota 23.

51 Decreto sobre extranjería y nacionalidad, 30 de enero de 1854, Compilación, 2000: 57-61. 
derecho sobre la igualdad jurídica, garantizar la eficiencia de la acción estatal, y constituir los mecanismos para resistir a los embates de la diplomacia de las cañoneras. De esta forma, la Ley fundamental determinó que solo los ciudadanos podían reunirse para «tomar parte en los asuntos políticos de la nación», ratificó la facultad del gobierno de expulsar al extranjero que le pareciera «pernicioso» y determinó, por voto unánime de los constituyentes, que eran mexicanos, además de los nacidos de padres mexicanos y aquellos que optaran por naturalizarse, los extranjeros «que adquieran bienes raíces en la República o tengan hijos mexicanos, siempre que no manifiesten la resolución de conservar su nacionalidad» ${ }^{52}$. En el proceso de naturalización, entonces, la adhesión voluntaria pasaba a segundo plano. La prioridad era la extensión necesaria y eficaz de la jurisdicción gubernamental.

En la década de 1880, al redactar el proyecto de una nueva ley de extranjería, el notable jurisconsulto Ignacio L. Vallarta buscaría «desenvolver y reglamentar los principios fundamentales de la Constitución», reconciliarlos con «el derecho de gentes» y dar «un testimonio irrefragable de la civilización de México», todo para

abrir de par en par las puertas de la República al extranjero que quiera establecerse, pero evitando las especulaciones de los aventureros que vienen solo a explotar nuestras desgracias ${ }^{53}$.

El antiguo secretario de relaciones celebraba entonces que México - a diferencia de los Estados Unidos - se hubiera puesto a la altura del resto del mundo civilizado al aceptar como base de la ciudadanía la nacionalidad del padre, y no el lugar de nacimiento. Con esto el país dejaba atrás «uno de los últimos vestigios del feudalismo», al reconocer que las «afecciones personales» eran más fuertes que las «locales», y al dar cabida al «reclamo» de la «sangre mexicana» ${ }^{54}$.

En cambio, Vallarta deploró que la constitución buscara imponer la nacionalidad mexicana a quienes invirtieran en bienes raíces o procrearan en el territorio nacional, «sino como pena, al menos como forzada compensación del derecho de poseer propiedades inmuebles». Se trataba de un mecanismo peligroso - en tanto que un extranjero «indigno de la naturalización», que podía ser incluso «enemigo de la República» podía contarse entre sus ciudadanos con solo comprar un pedazo de tierra, lo que de ninguna manera ga-

52 Constitución, febrero 5, 1857, Sección 1, art. 9; sección III, art. 33; sección II, art. 30. Aprobado por unanimidad, agosto 26, 1856, Zarco, 2007: 296. Véase Chenillo, 2009.

53 Vallarta, 1885: 305-306.

54 Vallarta, 1885: 307-310. 
rantizaba «la fidelidad»—. La norma estaba «en pugna con los dictados de la razón» y con «las exigencias de la justicia». El «considerar la nacionalidad como castigo» era un «despropósito» que no cabía ni «entre los salvajes», y que violaba el derecho internacional: el cambio de nacionalidad debía ser un «acto esencialmente voluntario» ${ }^{55}$. No obstante la indignación y la claridad mental del abogado jalisciense, su proyecto de ley conservó los defectos del enunciado constitucional: no hizo sino reglamentar lo establecido por la constitución: los extranjeros sujetos a la naturalización automática al comprar tierras o tener hijos, tenían seis meses para declarar si querían conservar su nacionalidad originaria. El proyecto de ley apenas se debatió, sin que este tema en particular fuera abordado. Fue aprobado con un solo voto en contra. Se reformaría pocos días después, para extender el periodo de definición a ocho meses ${ }^{56}$. El restringir el recurso de los extranjeros a la protección diplomática - por lo menos a aquéllos que se despistaran al escriturar una propiedad o registrar a uno de sus vástagos - resultó una tarea de construcción estatal más importante que el establecimiento de una relación voluntaria y recíproca entre individuo y estado.

\section{Algunas CONCLUSIONES}

Las políticas de naturalización en México y en Estados Unidos a lo largo del siglo XIX respondieron por un lado a las exigencias de un nuevo orden político, articulado - no siempre de forma transparente o consistente- por el consentimiento de individuos libres. Por el otro, se vieron moldeadas por las tensiones que estructuraban la política partidista y la relación entre los gobiernos federal - o nacional, bajo las constituciones centralistas en México- y estatales, y, sobre todo en el caso de México, por la necesidad de afianzar la autoridad estatal y lidiar con las presiones diplomáticas. En ambos países, en un proceso discontinuo y sinuoso, el poder federal se impuso sobre las iniciativas locales para normar asuntos de ciudadanía, destacando, en los Estados Unidos, el papel del poder judicial, que ratificó los lineamientos que debían seguir tanto el gobierno federal como los estatales en sus políticas

55 Vallarta, 1885: 318-319. En la práctica, sin embargo, el no acudir a la Secretaría de relaciones para obtener la carta de naturalización dentro del plazo de un año que marcaba la ley constituyó una razón para negar la naturalización a quienes la solicitaban por este medio.

56 Diario de debates, LIX legislatura, Senado, 25 de mayo de 1886: 426-427. Decreto 28 de mayo de 1886, Compilación, 2000: 93-101. 
hacia los extranjeros. Para principios del siglo XX, puede decirse que, para regular la pertenencia de quienes venían de fuera y querían integrarse a la sociedad local, el gobierno federal estadounidense se erigía autoridad nacional. En el caso mexicano, las normas de naturalización se centraron en el poder ejecutivo, ahí donde un gobierno receloso intentaba evitar la injerencia de las potencias.

Así, durante la segunda mitad del siglo, el convertirse en ciudadano mexicano tuvo que ver tanto - y a veces más - con la necesidad del gobierno mexicano por afianzar su jurisdicción que con la voluntad y el compromiso del futuro integrante de la comunidad. Por otra parte, el carácter burocrático del proceso puso al gobierno mexicano, a pesar de la inestabilidad y su falta de recursos, delante de su vecino del norte en cuanto a la catalogación, registro e identificación de los extranjeros residentes: así, mientras que, en México, prácticamente desde la independencia (Reglamento para la admisión de Extranjeros, febrero 1, 1823), se emitía un pasaporte a los extranjeros que entraban en territorio nacional, los Estados Unidos no registraron su llegada sino hasta 1818. Desde principios de la década de 1880, las autoridades mexicanas exigían a los solicitantes enviar fotografías para pegar sobre las cartas de naturalización. En Estados Unidos, no fue sino hasta la promulgación de ley de 1906 que empezó a exigirse que se plasmara, en la declaración de intención, la descripción física —altura, complexión, color de ojos y cabello- del solicitante.

En los inicios de la vida independiente, y a pesar de los problemas e indefiniciones con los que lidiaron, ambas naciones instituyeron a la naturalización como un proceso abierto a todo hombre «bueno» - que no podía ser, en Estados Unidos, sino blanco, y en México católico-, dispuesto a cambiar de domicilio, a renunciar a sus viejas lealtades, y a abrazar la fe republicana - con la que no tenían, necesariamente, que estar familiarizados- Se trataba, a fin de cuentas, de construir una comunidad cívica vinculada por la ley y un destino común, no por lazos personales ni por un pasado compartido. Al mediar el siglo en México, y en los albores del siglo XX en Estados Unidos, las leyes de naturalización, y las prácticas que se desarrollaron alrededor del proceso constituyeron un testimonio de cómo había cambiado la percepción que de sí mismas habían construido estas sociedades americanas. En Estados Unidos, la definición del ciudadano potencial se amplió para incluir no solo lo que el solicitante era y quería ser, sino lo que sabía y en qué creía. La ley creó además una serie de requisitos burocráticos para salvaguardar el proceso de naturalización de la corrupción y el fraude que según muchos de los legisladores mermaban a la democracia americana. En México, el Estado, en con- 
tra de la convicción de algunos de sus artífices más brillantes, buscó imponer la naturalización a los extranjeros que adquirían intereses económicos o familiares en México, y no rechazaban de forma explícita la iniciativa del gobierno mexicano: se trataba, no de acrecentar a la masa ciudadana, sino de reforzar al Estado. La República se había tornado frágil.

\section{REFERENCIAS CONSULTADAS}

\section{ARCHIVO}

NARA. National Archives Record Administration. Estados Unidos de América.

\section{BIBLIOGRAFÍA}

Aleinikoff, T. Alexander, Semblances of Sovereignty: The Constitution, the State and American Citizenship, Cambridge, Harvard University Press, 2002.

Armitage, David, The Declaration of Independence. A Global History, Cambridge, Harvard University Press, 2007.

Baseler, Marilyn C., Asylum for Mankind: America, 1607-1800, Ithaca, Cornell University Press, 1998.

Bradburn, Douglas, The Citizenship Revolution: Politics and the Creation of the American Union, 1774-1804, Charlotte, University of Virginia Press, 2009.

Brown, Matthew, «Inca, Sailor, Soldier, King: Gregor MacGregor and the early nineteenth-century Caribbean», Bulletin of Latin American Research, 24:1 (Londres, 2005): 44-71.

Brown, Wallace, The King's Friends. The Composition and Motives of the American Loyalist Claimants, Providence, Brown University Press, 1965.

Chenillo, Paola, «Entre la igualdad y la seguridad. La expulsión de extranjeros en México a la luz del liberalismo decimonónico, 1821-1876», tesis (licenciado en historia), el autor, UNAM, 2009.

Ciaramitaro, Fernando, Italiani tra Spagna e Nuevo Mondo. Colonie, famiglie e singoli emigrante in antico regime (secoli $X V-X V I I I)$, Catania, Universitá di Catania, 2006.

Cleveland, Sarah H., «Powers Inherent in Sovereignty: Indians, Aliens, Territories, and the Nineteenth Century Origins of Plenary Power over Foreign Affairs», Texas Law Review, 81/1 (Austin, 2002): 3-284. 
Compilación histórica de la legislación migratoria en México. 1821-2000, segunda edición corregida y aumentada, México, Secretaría de Gobernación, 2000.

Croxton, Frederick C., Statistical Review of Inmigration, 1820-1910. Distribution of Immigrants, 1850-1909, Washington, Government Printing Office, 1911.

De León, Arnoldo, In Re Ricardo Rodríguez: An Attempt at Chicano Disenfranchisement in San Antonio, 1896-1897, San Antonio, Caravel Press, 1979.

Documentos históricos para la historia del México Independiente. Insurgencia y República Federal. 1808-1824, estudio histórico y selección, Ernesto Lemoine. México, Banco Internacional, Miguel Ángel Porrúa, 1986.

Dublán, Manuel y Lozano, José María, Legislación mexicana o colección completa de las disposiciones legislativas expedidas desde la Independencia de la República, México, 1876-1904, en http://biblioweb.dgsca.unam.mx/dublanylozano.

Foley, Neil, «Straddling the Color Line: The Legal Construction of Hispanic Identity», Nancy Foner and George Fredrickson (eds). Not Just Black and White: Historical and Contemporary Perspectives on Immigration, Race, and Ethnicity in the United States, Nueva York, Russell Sage Foundation, 2004: 341-357.

Franklin, Frank George, The Legislative History of Naturalization in the United States from the Revolutionary War to 1891, Chicago, University of Chicago, 1905.

Haney Lópéz, Ian, White by Law: The Legal Construction of Race, Nueva York, New York University Press, 1997.

Herzog, Tamar, Defining Nations. Inmigrants and Citizens in Early Modern Spain and Spanish America, New Haven, Yale University Press, 2003.

Kettner, James «The Development of American Citizenship in the Revolutionary Era: The Idea of Volitional Allegiance», The American Journal of Legal History, XVIII (Filadelfia, 1974): 208-266.

Kettner, James, The Development of American Citizenship, 1608-1870, Chapel Hill, University of North Carolina Press, 1978.

LeMay, Michael C. y Barkan, Elliot R. (eds.), US Immigration and Naturalization Laws and Issues. A Documentary History, Westport, Greenwood Press, 1999.

Meyer Cosío, Rosa María, «Empresarios españoles después de la independencia», Beatriz Rojas (coord.), El poder y el dinero. Grupos y regiones mexicanos en el siglo XIX, México, Instituto Mora, 1999: 218-255.

Mongey, Vanessa, «Les vagabonds de la république: les révolutionnaires européens aux Amériques», Federica Morelli, Clément Thibaud y Géneviève Verdo (coords.), Les empires atlantiques des Lumières au libéralisme (1763-1865), Rennes, Presses Universitaires de Rennes, 2009: 67-82.

Pani, Erika «Saving the nation through Exclusion: Alien Laws in the Early Republic in the United States and Mexico», The Americas, 65/2 (Filadelfia 2008): 217-246. 
Pani, Erika, «Ties Unbound. Membership and Community during the Wars of Independence. The Thirteen North American Colonies (1776-1783) and New Spain (1808-1821)», Federica Morelli, Clément Thibaud y Géneviève Verdo (coords.), Les Empires Atlantiques. Des Lumières au Libéralisme (1763-1865), Rennes, Presses Universitaires de Rennes, 2009: 39-66.

Pi-Suñer, Antonia, «Negocios y política a mediados del siglo XIX», Clara E. Lida (coord.), Una inmigración privilegiada. Comerciantes, empresarios y profesionales españoles en México en los siglos XIX y XX, Madrid, Alianza, 1994: 75-96.

Pi-Suñer, Antonia, La deuda española en México. Diplomacia y política en torno a un problema financiero, 1821-1890. México, El Colegio de México, UNAM, 2006.

Rabadán, Macrina, «Ser o no ser... español en México. Los vaivenes de la definición y elección de la nacionalidad, 1821-1857», Estudios 76 (México, 2006): 65-93.

Reséndez, Andrés (ed.), A Texas Patriot on Trial in Mexico:José Antonio Navarro and the Texas Santa Fe Expedition, Dallas: DeGoyler Library, Clements Center for Southwest Studies, 2005.

Rojas, Rafael, Las repúblicas de aire. Utopía y desencanto en la revolución de Hispanoamérica, México, Taurus, 2009.

Salyer, Lucy E., Laws Harsh as Tigers. Chinese Immigrants and the Shaping of Modern Immigration Law, Chapel Hill, University of North Carolina Press, 1995.

Schuck, Peter H., «The Transformation of Immigration Law», Columbia Law Review, 84/1 (Nueva York, 1984): 1-90.

Tena Ramírez, Felipe, Leyes fundamentales de México, 1808-2002, México, Editorial Porrúa, 2002.

Tenebaum, Barbara A., México en la época de los agiotistas, 1821-1857, México, Fondo de Cultura Económica, 1985.

Vallarta, Ignacio L., Exposición de motivos del Proyecto de Ley sobre extranjería y naturalización que por encargo de la Secretaría de relaciones exteriores ha hecho el Lic..., México: Imprenta de Ignacio Cumplido, 1885, en línea www.bibliojurídica.org/libros/2/942/15.pdf.

Wahnich, Sophie, L'impossible citoyen. L'étranger dans le discours de la Révoution Française, París, Albin Michel, 2010.

Zarco, Francisco, Historia del Congreso constituyente de 1857, México, Senado de la República, 2007.

Zimmerman, James F., Impressment of American Seamen, Nueva York, Columbia University Press, 1925.

Fecha de recepción: 24 de mayo de 2011

Fecha de aceptación: 12 de febrero de 2012 


\section{Transforming Aliens: Naturalization Policies in North America. The United States and Mexico in the Nineteenth Century}

This article explores, within a comparative framework, the evolution of naturalizaton law in two "new» North American countries, from independence to the early XX century, when the «Open Door Era» of immigration policy, which generally welcomed those coming from abroad, came to an end. It hopes to show how naturalization policies became spaces, on the one hand, for the expression of republican ideals of membership and, on the other, for the intervention of political authority -first at the state, then at the federal level-in order to regulate the political community.

KeY words: Mexico; United States; naturalization; immigration; republicanism. 